\title{
A proposition for a cancer treatment study using radioactive metal co-factor enzymes
}

\author{
Luyen Van Tran
}

Former senior researcher, Vietnam Atomic Energy Commission (VAEC) Hanoi, Vietnam

Email: luyen.tranvan@gmail.com History

- Received: Oct 18, 2018

- Accepted: Jan 20, 2019

- Published: Feb 17, 2019

DOI :

https://doi.org/10.15419/bmrat.v6i2.519

\section{Check for updates}

\section{Copyright}

(-) Biomedpress. This is an openaccess article distributed under the terms of the Creative Commons Attribution 4.0 International license.

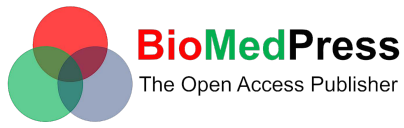

\begin{abstract}
Cancer is a serious pathological condition of abnormal cells are gathered in tumors in the body's tissues or organs. Due to their accelerated metabolism, cancer cells require a great demand for energy, protein (cell structure substrates), and metabolic enzyme activity. If the body does not respond adequately to this demand, the metabolic processes of cancer cells will be hampered, and their growth will be limited or even stopped. It is possible to control the metabolic processes of the cancerous tumors by performing one or more of the following approaches: stopping the energy and cell structure substrate supply, inhibiting enzymic activity, and/or destroying cancer cells with external agents (such as radiation and/or chemicals). These approaches have been investigated either in single or combination modes, but so far the results obtained have not been on par with expectations. In this paper, we propose a method of cancer treatment which entails the use of a radioisotope instead of stable metal to break down the structure of metal co-factor enzyme and to deactivate its catalytic function. With a judicious choice of the metal radioisotope, this method is even able to perform all the above-mentioned approaches, and at the same time, giving a much better efficacy in cancer treatment.

Key words: beta decay, electron capture, Enzyme, $M^{*}$-enzyme, $M$-enzyme, metal cofactorenzyme, nuclear recoil, nuclear transformation, radioisotope-enzyme
\end{abstract}

\section{INTRODUCTION}

Cancer disease is a big challenge to human health. Nowadays, efforts have been made towards finding a treatment for cancers, however, the results have not yet been satisfactory ${ }^{1-5}$. Cancer cells have a great demand for energy and proteins, which requires a high enzymic activity. Based on these requirements, it is possible to control or stop the metabolic processes in cancer cells by performing one or more of the following approaches:

(a) preventing the energy supply;

(b) terminating the supply of cell structure substrates;

(c) terminating the catalytic activity of metabolic enzymes (by deactivating them and/or breaking down their structures); and

(d) destroying cancerous cells via external agents (such as radiation and/or chemicals).

Among these approaches, stopping the catalytic activity of metabolic enzymes can play an important role in preventing the reproduction process of cancer cells. Enzymes are classified into two main categories: pure protein-enzymes and co-factor-enzymes. The co-factor-enzymes can accept metal as a co-factor. Hereafter, the metal co-factor-enzyme will be denoted M-enzyme. The stability of M-enzyme depends on the stability of its components.
In this study, we are interested in the stability of the metal co-factor enzyme. If the metal is unstable, the enzyme will also be unstable. Its structure will be broken and/or its catalytic function will be disrupted. By replacing a stable metal $M$ with its radioisotope $M^{*}$, this unstable nuclide will be transformed into another element by $\beta$-decay or electron capture, thus deactivating the catalytic function of the enzyme involved in cancer cell reproduction process.

\section{HYPOTHESIS/OPINION}

It is well-known that $\beta$-decay and electron capture can transform a metal element $\mathrm{M}$ into another element that stands just before (hereafter denoted $\mathrm{X}$ ) or just after (denoted Y) the element $\mathrm{M}$ in the Periodic Table of Elements.

Clearly, we can replace the metal $\mathrm{M}$ in an M-enzyme by using one of its radioisotopes $\mathrm{M}^{\star}$, which will transform itself into $\mathrm{X}$ or $\mathrm{Y}$ as mentioned above. This is feasible because $M$ and $M^{*}$ are chemically identical; thus, the $\mathrm{M}^{*}$-enzyme biosynthesis process in the body is similar to the M-enzyme biosynthesis process. On the other hand, $\mathrm{M}^{\star}$ can be produced in local or nearby nuclear research facilities.

The replacement of $\mathrm{M}$ by $\mathrm{M}^{\star}$ can lead to the nuclear transformation of $\mathrm{M}^{\star}$ into $\mathrm{X}$ or $\mathrm{Y}$. As a result, 
the $M^{\star}$-enzymes will be deactivated . The cancer cell metabolism will be perturbed. New $\mathrm{M}^{\star}$-enzymes will continue to be created due to the need for the synthesis of substances in the remaining cancer cells until the last $\mathrm{M}^{*}$ available.

When the cofactor radioisotopes in enzyme molecules are transformed, not only do they generate particles and bremsstrahlung (in $\beta$-decay case) but they also emit other radiations, such as $\gamma$ - and X-rays (in both $\beta$-decay and electron capture cases). Most enzyme molecules are concentrated in the extracellular fluid of cancer cells, whereas biochemical reactions for bringing nutrients and metal ions into the cell occur on the cell membrane. In addition to the deactivation of $\mathrm{M}^{\star}$-enzyme, nuclear transformation processes also irradiate in-situ the neighboring cancer cells, with the shooting probability of almost one hundred percent. Moreover, the recoil nuclei from $\beta$-decay in $\mathrm{M}^{*}$-enzymes might have enough energy to break down the structure of an enzyme or protein molecule situated in its pathway. Another important effect of radiation is the generation of free radicals, such as $\mathrm{H}^{+}, \mathrm{OH}^{-}$, and $\mathrm{H}_{2} \mathrm{O}_{2}$. These free radicals will, in turn, interfere with metabolic processes in cancer cells. They can damage DNA structure, oxidize substrate molecules and, deactivate other enzymes.

This proposed method may present a side effect, due to possible $\mathrm{M}^{*}$ nuclear transformation outside the cancer tumor area. If $\mathrm{M}^{*}$ is injected directly into the tumor, this side effect will no longer be significant. The remaining problem is the internal radiation on the tissues outside the tumor by high-energy $\mathrm{b}$ particles, $\gamma$ - and X-rays, and bremsstrahlung due to $\mathrm{M}^{\star}$ nuclear transformations inside the tumor. However, $\mathrm{M}^{\star}$ dosage for each intravenous injection can be estimated to limit these internal radiation to the levels significantly lower than the commonly accepted levels in external irradiation methods.

In summary, the replacement of stable metal $\mathrm{M}$ by its radioisotope $M^{*}$ in $M$-enzymes is a new concept in cancer treatment, which applies M-enzyme deactivation and tumor cell destruction based on in-situ internal irradiation.

However, to confirm the proposed assumptions, we first have to perform the following work:

(1) Searching and classifying all M-enzymes present in different types of cancer, then obtaining chemical and nuclear characteristics of the related metals.

(2) Producing radioisotope $M^{\star}$ of these metals which meet the following conditions:

- Being $\beta$-decay or electron capture nuclides with high nuclear...transformation probability.
- Having a long half-life to be transported to tumor cells and having sufficient medical operation time.

(3) Finding appropriate carrier solutions to bring $M^{\star}$ to the enzyme biosynthesis areas, where the protein can find the right metal to create $\mathrm{M}^{\star}$-enzymes.

(4) The limitation of the proposed method is that healthy tissues around the cancerous tumor could also be irradiated. To avoid this harmful effect, it is necessary to apply a simulation method to estimate the dose distribution of beta and other radiations for each type of radioisotope and the optimal doses to be used. Other side effects have also to be carefully studied.

To illustrate the deactivation of metal cofactor enzymes, we will take an example of Hexokinase, which is the most important enzyme in the cancer development process because it is involved in the cell energy supply cycle (Figure 1). Hexokinase uses Magnesium $(\mathrm{Mg})$ as a co-factor. Since Hexokinase concentration is about 200 times higher in cancer cells than in normal cells ${ }^{6}$, the demand for Mg in hexokinase biosynthesis in the tumor region is very high. $\mathrm{Mg}-28^{7}$ is a radioisotope of Magnesium with a half-life of 21.3 hours. If $\mathrm{Mg}-28$ is injected into the body or the tumor, it will be involved in hexokinase synthesis, similarly as Mg. Mg-28 will emit beta particles accompanied by photons and multiple $\mathrm{X}$-rays and will decay to form radioisotope Al-28 that will decay itself to form stable Si-28. Al-28 has a half-life of 2.4 minutes. It will emit a high-energy beta particle together with a photon and multiple $\mathrm{X}$-rays. Both radioisotopes will irradiate in situ tumor cells with high accuracy. However, $\mathrm{Al}$ and $\mathrm{Si}$ are no longer cofactors in Hexokinase, and thus the enzyme loses its catalytic function or is deactivated. Thus, the energy supply to cancer cells is limited, preventing the development of tumors.

There are many co-factor metals M-enzymes ${ }^{9}$. Apart from $\mathrm{Mg}$-enzyme, the co-factor metals include: $\mathrm{Mn}$, $\mathrm{Ca}, \mathrm{Mo}, \mathrm{Co}, \mathrm{Fe}, \mathrm{Zn}, \mathrm{K}, \mathrm{Na}$, and $\mathrm{Ni}$; which should be investigated in future studies.

\section{CONCLUSIONS}

To conclude, our proposed method related to the use of $\mathrm{M}^{*}$-enzymes can lead to a better combination of two traditional cancer treatment methods (chemotherapy and radiotherapy). This method has the following advantages:

(1) It can deactivate M-enzymes and stop their catalytic functions by $\mathrm{M}^{\star}$ nuclear transformation.

(2) It can in situ irradiate and destroy tumor cells by beta-particles, $\gamma, \mathrm{X}$ and bremsstrahlung radiations, and break down protein molecules and other substrates by free oxidation radicals generated along radiation pathway. 


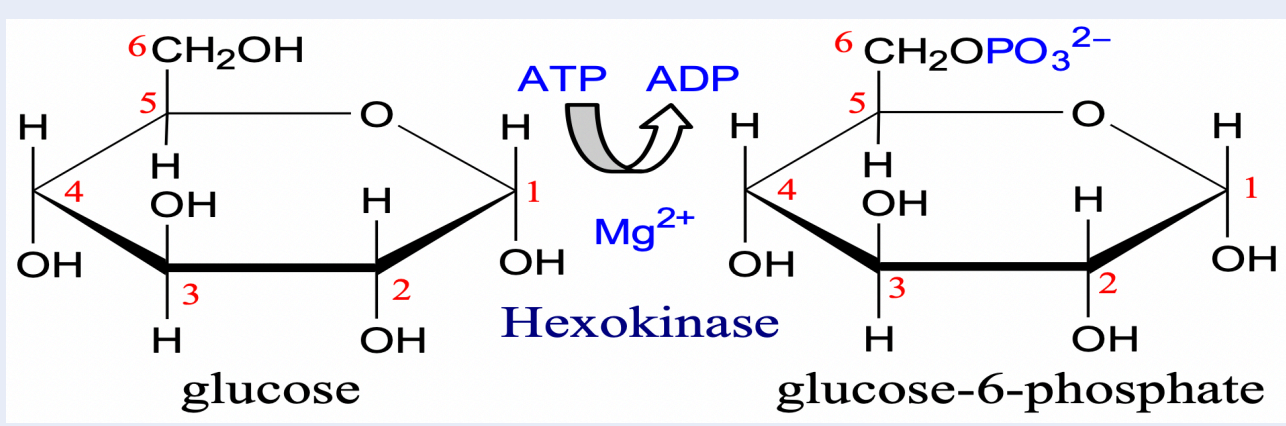

Figure 1: Hexokinase enzyme ${ }^{8}$ catalyzes the reaction to supply energy to the cell. $\mathbf{M g}^{2+}$ will change to $\mathrm{Al}^{3+}$ and then Si after both $\mathrm{Mg}-28$, and Al-28 decays, resulting in the enzyme being inactivated.

It is generally capable to perform almost all steps simultaneously to control the metabolic process of cancer cells. For Mg-28 used as $\mathrm{Mg}^{*}$, all four measures can be performed. This report presents new ideas for cancer treatment which have not been supported yet by empirical evidence. The author wishes to start this study and are willing to co-operate with other research groups to clarify the contents of this article and to design specific experiments to turn these ideas into reality.

\section{CONFLICT OF INTEREST}

The author reports no conflicts of interest in this work.

\section{AUTHORS' CONTRIBUTIONS}

The author is a nuclear physicist, analyzing the trace essential elements in biomaterials for a long time. Most of these elements are metals. It is known that these elements play an important role in co-factor enzyme. It has been questioned about: "what would happen if the metals in the co-factor enzyme are unstable" ?. The answer is clear. The enzyme is deactivated and then the biosynthesis governed by the enzyme is disturbed.

\section{ACKNOWLEDGMENTS}

We are grateful to Dr. Ha Anh Tran, former director of Dalat Nuclear Research Institute and to Dr. Chan $\mathrm{Tu}$ for giving comments on the content of this work.

\section{REFERENCES}

1. Rosenberg SA, Harris S, McLaughlin MA, editors. Principles and Practice of Biology Therapy of Cancer. Philadelphia, PA, USA: Lippincott Williams \& Wilkins; 2000.

2. Beard J, Gonzalez NJ, editors. The enzyme treatment of cancer and its scientific basic. New Spring Press; 2009.

3. Anastasiou D, Yu Y, Israelsen WJ, Jiang JK, Boxer MB, Hong BS. Pyruvate kinase $\mathrm{M} 2$ activators promote tetramer formation and suppress tumorigenesis. Nat Chem Biol. 2012;8(10):839-47. Available from: 10.1038/nchembio.1060.

4. Michalik L, Desvergne B, Wahli W. Peroxisome-proliferatoractivated receptors and cancers: complex stories. Nat Rev Cancer. 2004;4(1):61-70. Available from: 10.1038/nrc1254.

5. Sergina NV, Rausch M, Wang D, Blair J, Hann B, Shokat KM. Escape from HER-family tyrosine kinase inhibitor therapy by the kinase-inactive HER3. Nature. 2007;445(7126):437-41. Available from: 10.1038 /nature 05474 .

6. Bustamante E, Pedersen PL. High aerobic glycolysis of rat hepatoma cells in culture: role of mitochondrial hexokinase. Proc Natl Acad Sci USA. 1977;74(9):3735-9. Available from: 10.1073/ pnas.74.9.3735.

7. Alburger DE, Harris WR. Decay Scheme of Mg-28. Phys Rev. 1969;1969(185):1495.

8. Website; Available from: http://biosiva.50webs.org/glycol.htm.

9. Jeske L, Placzek S, Schomburg I, Chang A, Schomburg D. BRENDA in 2019: a European ELIXIR core data resource. Nucleic acids research. 2019;47:D542-D549. Available from: 10.1093/ nar/gky1048; https://www.ncbi.nlm.nih.gov/pubmed/30395242. 